\title{
Combination of direct intratumoral administration of dendritic cells and irradiation induces strong systemic antitumor effect mediated by GRP94/gp96 against squamous cell carcinoma in mice
}

\author{
YASUNORI AKUTSU, HISAHIRO MATSUBARA, TETSURO URASHIMA, AKI KOMATSU, \\ HARUHITO SAKATA, TAKANORI NISHIMORI, YASUO YONEYAMA, ISAMU HOSHINO, \\ KENTARO MURAKAMI, AKIHIRO USUI, MASAYUKI KANO and TAKENORI OCHIAI \\ Department of Frontier Surgery, Graduate School of Medicine, Chiba University, \\ 1-8-1 Inohana, Chuo-ku, Chiba 260-8670, Japan
}

Received April 2, 2007; Accepted May 29, 2007

\begin{abstract}
We tested a new therapeutic modality for head and neck and esophageal cancers, a combination of direct intratumoral (i.t.) administration of dendritic cells (DCs) and radiation therapy (RT) in mouse squamous cell carcinoma (SCC). We also evaluated the functions of gp96, which can enhance systemic antitumor activity, and the mechanism of the abscopal effect. Mouse SCC cells $\left(1 \times 10^{5}\right)$, SCCVII, were inoculated into the left femur of $\mathrm{C} 3 \mathrm{H} / \mathrm{He}$ mice subcutaneously, and also similarly inoculated into chest subcutaneous tissue. Only the left femur tumor was exposed to 4 or 10 Gy of ionizing radiation, and then $1 \times 10^{6}$ DCs i.t. was injected only into the femur tumor. Following this procedure, tumor volumes of the femur and chest were measured. We evaluated whether gp96 could enhance the antitumor effect. With DCs i.t. and RT, tumor growth was markedly suppressed. Tumor growth of non-treated tumors were also suppressed, indicating that the combination therapy of DCs and RT evoked systemic antitumor activity. In vitro, the enhancement of gp96 expression was strongly detected by immunostaining after irradiation, DCs with gp96 induced strong cytotoxic activity in vitro, and tumor growth inhibition was observed by direct i.t. injection of gp96. A combination of DCs i.t. and RT can induce a strong antitumor effect not only against treated local tumor but also against non-treated distant tumor, indicating that this treatment can evoke a strong systemic antitumor effect. Gp96 is thought to be one of the target molecules to explain the abscopal effect.
\end{abstract}

Correspondence to: Dr Yasunori Akutsu, Department of Frontier Surgery, Graduate School of Medicine, Chiba University, 1-8-1 Inohana, Chuo-ku, Chiba 260-8670, Japan

E-mail: yakutsu@faculty.chiba-u.jp

Key words: dendritic cell, radiation, intratumoral administration, abscopal effect, squamous cell carcinoma, head and neck cancer, esophageal cancer

\section{Introduction}

Despite the recent advances in treatment, head and neck cancer and esophageal SCC (squamous cell carcinoma) are still among the worst malignant neoplasms, especially in Asia. Their prognosis is miserable and unsatisfactory with the current treatments, as lymph node metastases and distant organ metastases occur frequently. Effective treatment is not yet established, and new therapeutic modalities are eagerly awaited.

DC (dendritic cell)-based immunotherapy is reported as an effective treatment in many types of cancers, but the usage of DCs alone is not always completely effective because of the poor antigenicity of cancer cells themselves. The precise reason why cancer can escape from the immune system of the host is still unclear. In recent years, various possibilities of combining immunotherapy and RT (radiation therapy) that would be able to achieve better local tumor control and systemic tumor control (1-5) have been discussed. RT has the ability to kill cancer cells, and RT-killed cancer cells can be a good source of tumor antigens for inducing CTL (cytotoxic T-lymphocyte) activation (6). Moreover, a recent study revealed that RT itself can elicit a systemic immunological antitumor effect (7) called the abscopal effect (8). However, direct evidence on how ionizing radiation can elicit a systemic antitumor immunoresponse is not available.

Heat shock protein gp96, also called glucose-regulated protein GRP94, is a stress protein that works as protein chaperone when DCs take up the antigen via surface molecule CD91 (9-12) to mediate CTL activation by Toll-like receptors 2 and 4 (13). We think that gp96 is a key molecule for explaining the mechanism of the abscopal effect. In this study, we evaluated the expression of gp96 induced by ionizing radiation and the function of gp96 for the enhancement of the immunoresponse both in vitro and in vivo. We present the usefulness of the combination therapy of direct DCs i.t. (intratumoral) and RT, which can induce strong antitumor effect not only against local but also distant non-treated tumor, using a mouse SCC model. This therapy gives hope to patients with head and neck and esophageal cancers. 


\section{Materials and methods}

Tumor and mice. Poorly immunogenic, mouse squamous cell carcinoma SCCVII tumor cells, kindly provided by Professor Yuta Shibamoto (Department of Quantum Radiology, Nagoya City University, Nagoya, Japan), were used in this study. The characteristics of these tumor cells have been well described (14). SCCVII cells were maintained in Eagle's minimum essential medium supplemented with $12.5 \%$ fetal bovine serum, penicillin and streptomycin $(100 \mu \mathrm{g} / \mathrm{ml})$, and 2-[4-(2Hydroxyethyl)-1-piperadinyl] ethansulfonic acid (10 mM). Syngeneic 6- to 10-week-old female $\mathrm{C} 3 \mathrm{H} / \mathrm{He}$ mice, purchased from Japan SLC (Shizuoka, Japan), were maintained in our facility under specific pathogen-free conditions. Independent experimental groups were used, and each consisted of at least 3 mice. Animal care was in accordance with the guidelines of Chiba University.

DCs generation. DCs were generated using the method established by Lutz et al (15). Cells were prepared from BM (bone marrow) cells of femurs and tibias. First, BM cells were left in $70 \%$ ethanol for 2-5 min for disinfection, washed with PBS (phosphate-buffered saline) 2 times, and then flushed with PBS using a 27-gauge injection needle. On day $0,2 \times 10^{6} \mathrm{BM}$ cells in $10 \mathrm{ml}$ of RPMI-1640 medium supplemented with penicillin $(100 \mathrm{U} / \mathrm{ml})$, streptomycin $(100 \mu \mathrm{g} / \mathrm{ml})$, L-glutamine (2 mM), 2-mercaptoethanol $(50 \mu \mathrm{M}), 10 \%$ fetal bovine albumin, and $200 \mathrm{U} / \mathrm{ml}(20 \mathrm{ng} / \mathrm{ml}) \mathrm{rmGM}-\mathrm{CSF}$ (recombinant mouse granulocyte-colony stimulating factor) (G0282, Sigma, Tokyo, Japan) were placed into 100-mm diameter Petri dishes (Falcon ${ }^{\mathrm{TM}}$ No. 1029, BD, San Jose, CA, USA). On day 3, another $10 \mathrm{ml}$ of the medium with supplements was added to the dishes. Non-adherent cells were harvested on day 6 for use as DCs.

Flow cytometry. Cells were first treated with mouse BD Fc Block (2.4G2, Pharmingen ${ }^{\mathrm{TM}}$, BD) and then stained with antibodies conjugated with fluorescent agents. For analysis of the surface markers of DCs, anti-mouse CD11C-FITC (BD-557400, BD), anti-mouse CD80-PE (BD-553769, BD), anti-mouse CD86-PE (BD-553692, BD) and anti-mouse I-Ab (BD-553605, BD) were used. For the investigation of CTLs in TDLN (tumor drainage lymph node)s, CD3-PE (2134-0034, Biogenesis, Kingston, NH, USA) and CD8-FITC (2134-0083, Biogenesis) were used. Cell count was performed with a Coulter Epics XL cytometer (Beckman Coulter, Miami, FL, USA), and cell populations were evaluated with gating software, FlowJo for Windows (Tree Star Inc., Ashland, OR, USA).

Fluorescent staining of gp96 in SCCVII cells in vitro. SCCVII cells $\left(1 \times 10^{6}\right)$ were exposed to 2 Gy of ionizing radiation. Twenty-four hours later, cells were collected and stained with anti-mouse-gp96 (SPA-850, Stressgen, Ann Arbor, MI, USA) and fluorescein-conjugated secondary antibody (Chemicon, Temecula, CA, USA). The expression of gp96 was observed with a laser microscope (Carl Zeiss, Oberkochen, Germany).

Western blot analyses. Protein extracts were separated by electrophoresis on $10 \%$ polyacrylamide gel. The proteins were transferred to polyvinylidene fluoride membranes (Millipore, Bedford, MA, USA) in a tank transfer apparatus (Bio-Rad, Hercules, CA, USA), and the membranes were blocked with 5\% skim-milk in PBS. Rat anti-GRP94 monoclonal antibody (SPA-850, Stressgen) diluted to 1:2000 in blocking buffer was used as primary antibody, and goat anti-rat IgG: horseradish peroxidase Conj (SAB-200, Stressgen) diluted to 1:5000 in blocking buffer was used as secondary antibody. Antigens on the membrane were detected by ECL ${ }^{\mathrm{TM}}$ detection reagents (Amersham Biosciences, Piscataway, NJ, USA).

Cytotoxic activity mediated by DCs pulsed with/without antigen and with/without gp96. To generate antigen, WTL (whole tumor lysate) was made. Viable SCCVII tumor cells were suspended at $1 \times 10^{7} / \mathrm{ml}$ PBS and subjected to four cycles of rapid freeze (liquid $\mathrm{N}_{2}$ )/thaw $\left(37^{\circ} \mathrm{C}\right.$ water bath) exposure. Then they were spun at $1000 \mathrm{rpm}$ at $4^{\circ} \mathrm{C}$ for $5 \mathrm{~min}$ to remove cellular debris, and the supernatant was used as antigen. DCs were mixed with WTL at a ratio of 3 tumor cell equivalents: $1 \mathrm{DC}$ in complete medium or in complete medium including pathogen-free purified gp96 $(5 \mu \mathrm{g} / \mathrm{ml})$ eluted from mouse cells (IMA-200-1-C100, Immatics Biotechnologies, Tübingen, Germany). After $18 \mathrm{~h}$ of culture, DCs were harvested, washed twice with PBS, and resuspended at $1 \times 10^{6}$ cells $/ 0.1 \mathrm{ml}$ PBS for use as TP-DCs (tumor-pulsed DCs) or as gp96-pulsed TP-DCs (gp96-TP-DCs). Next, whole spleen cells of C3H/He mice were mixed with TP-DCs or with gp96-TP-DCs, and incubated for $24 \mathrm{~h}$. As target cells, SCCVII cells were labeled with $100 \mu \mathrm{Ci}$ of sodium chromate $\left({ }^{51} \mathrm{Cr}\right.$; Amersham Pharmacia Biotech, Uppsala, Sweden) for $1 \mathrm{~h}$ at $37^{\circ} \mathrm{C}$. Then, the mixture of DCs with splenocytes was co-cultured with ${ }^{51} \mathrm{Cr}$-labeled SCCVII cells for another $4 \mathrm{~h}$. Cytotoxic activities were evaluated at $\mathrm{E} / \mathrm{T}$ ratios of 100,50 and $25 .{ }^{51} \mathrm{Cr}$ release assay was conducted as previously described (16).

Tumor growth inhibition by direct i.t. administration of gp96 in vivo. We examined the effectiveness of direct i.t. administration of purified mouse gp96. SCCVII cells were inoculated into femur subcutaneous tissue, and $4 \mu \mathrm{g}$ of gp96 was directly injected into tumors on days 6,7 and 8 after the tumor inoculation. Tumors were measured on days $3,7,10$, $11,16,18,22,25,28$ and 32 , and tumor volumes were calculated.

CTLs in TDLNs. First, SCCVII cells at $1 \times 10^{5} / 50 \mu 1$ PBS were inoculated into the left femur subcutaneous tissue of $\mathrm{C} 3 \mathrm{H} / \mathrm{He}$ mice on day 0 . On days 6,7 and 8 , tumors were exposed to 10 Gy of radiation, and then DCs i.t. injection was performed on days 8,9 and 10 . On day 11 , mice were sacrificed and TDLNs were collected and washed with PBS. After red blood cell reduction, cells were stained with fluorescent conjugated anti-CD3 and anti-CD8, as described for the aforementioned flow cytometry. The population of $\mathrm{CD}^{+} / \mathrm{CD}^{+}$as a systemic cytotoxic reaction was evaluated.

Direct DCs i.t. with RT. For treated local tumor, SCCVII cells $\left(1 \times 10^{5}\right.$ cells $\left./ 50 \mu 1 \mathrm{PBS}\right)$ were inoculated into the left femur subcutaneous tissue of $\mathrm{C} 3 \mathrm{H} / \mathrm{He}$ mice on day 0 . Similarly, for non-treated distant tumor, SCCVII $\left(1 \times 10^{5}\right.$ cells $/ 50 \mu 1$ PBS) were inoculated into chest subcutaneous tissue. Before 


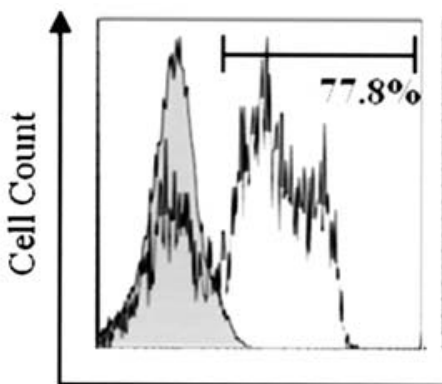

MHC-ClassII

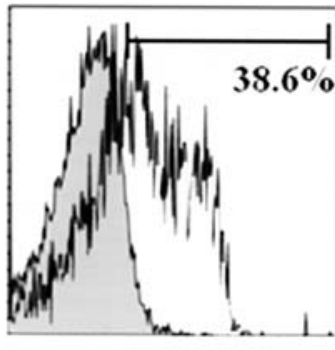

CD11c

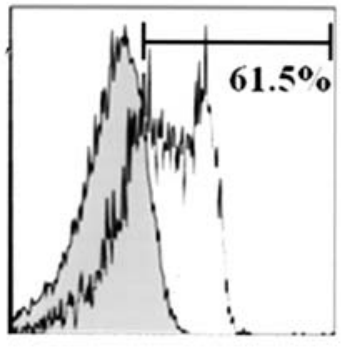

CD80

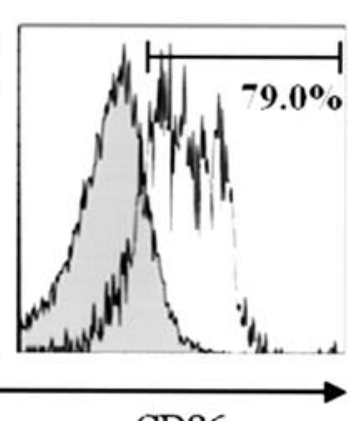

CD86

Figure 1. Cell surface phenotypes of BM-derived cells and DCs. BM-derived cells were cultured in the presence of rmGM-CSF and then stained for flow cytometry. Cultured cells presented high levels of MHC-class II, CD11c, CD80 and CD86 molecules (white) compared with BM-derived cells (gray).

a
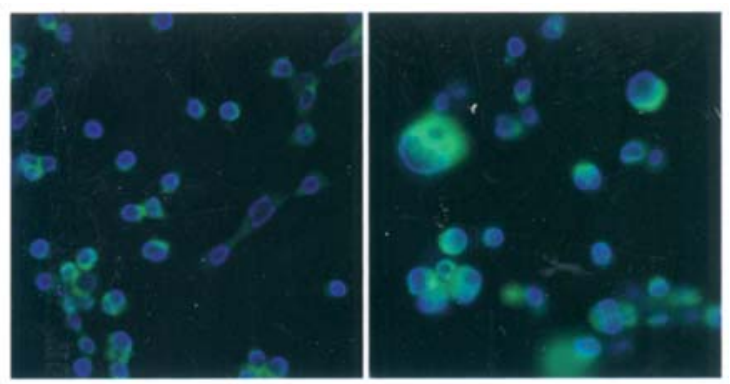

b

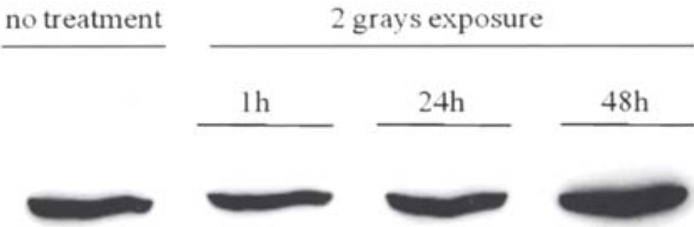

Figure 2. a, Fluorescent staining with anti-gp96-FITC antibody $24 \mathrm{~h}$ after exposure to $2 \mathrm{~Gy}$ of radiation. Compared with normal control (left), gp96 was well stained in tumor cells mainly at the cytoplasm, indicating that ionizing irradiation induced enhancement of gp96 expression (right). Cell ballooning was also observed in irradiated cells. b, Western blotting of gp96. SCCVII tumor cells were exposed to 2 Gy of ionizing radiation and analyzed by Western blotting 1, 24 and $48 \mathrm{~h}$ after the exposure. Gp96 protein was increased at $48 \mathrm{~h}$ after the irradiation compared with normal control.

DCs i.t., 4 Gy of ionizing irradiation was given only to the femur tumor on days 6,7 and 8 after tumor inoculation. To avoid systemic exposure by RT, the whole body except the femur tumor was covered with a lead shield. On day 8, 9, 10,12 and $14,1 \times 10^{6}$ DCs were directly administered only into the femur tumor. Both femur and chest tumors were measured on days $3,6,8,10,12,14,16,18,21,24,29,33$ and 38 , and tumor volumes were calculated.

\section{Results}

Surface markers of generated DCs. Because DCs generation according to Lutz et al (15) was a newly developed method, we first evaluated whether cells thus generated could be used as DCs. The surface markers of these cells treated with this technique are shown in Fig. 1. MHC (major histocompati- bility complex) class II, CD11c, CD80 and CD86 were highly expressed at 77.8, 38.6, 61.5 and $79.0 \%$, respectively. Accordingly, we used these cells as DCs.

Induction of gp96 by ionizing radiation, and cell ballooning. We examined whether the expression of gp96 could be induced by irradiation in vitro. When SCCVII cells were exposed to 2 Gy of irradiation, the induction of gp96 protein was detected especially in the cytoplasm by fluorescent staining as shown in Fig. 2a. Similarly, enhanced expression of gp96 was detected by Western blotting $48 \mathrm{~h}$ after irradiation (Fig. 2b). These results indicate that the expression of gp96 was stimulated by the stress of the irradiation. Additionally, cell ballooning was observed by laser microscopy.

Gp96 enhancement of cytotoxic effect in vitro and in vivo. We next evaluated whether gp96 could induce the activation of cytotoxic activity in vitro. As shown in Fig. 3a, the cell mixture of DCs, WTL, splenocytes and gp96 induced the strongest cytotoxicity against ${ }^{51} \mathrm{Cr}$-labeled SCCVII cells compared with the mixture without gp96. This implies that gp96 itself has the ability to stimulate DCs. Furthermore, DCs, gp96, and splenocytes, but without WTL, also induced cytotoxicity. Gp96 itself, without the need to identify specific tumor antigenic epitopes, could induce cytotoxicity, and can induce the maturation of DCs and elicit antitumor responses (17), whereas simple co-culture of DCs and splenocytes could not. Then, we evaluated the effectiveness of gp96 in vivo. As shown in Fig. 3b, slight growth suppression was observed when gp96 was i.t. administered. This indicated that gp96 itself can induce tumor suppression, which seems to be mediated by the DC-based immunoresponse as demonstrated in Fig. 3a.

Population of $\mathrm{CD}^{+} / \mathrm{CD} 8^{+}$T cells in TDLNs. We investigated whether DCs i.t. can elicit a systemic antitumor effect in vivo by detecting $\mathrm{CD}^{+} / \mathrm{CD}^{+} \mathrm{T}$ cells in TDLNs. As shown in Fig. 4, the $\mathrm{CD}^{+}{ }^{+} \mathrm{CD} 8{ }^{+}$population in TDLNs of the mice treated by both DCs i.t. and RT was about 2 times larger compared with those treated only with DCs i.t. This suggests that RT can effectively evoke systemic antitumor activity and that it can be a sensitizer of a DC-based immunoresponse. Furthermore, we also evaluated whether RT treatment alone has the possibility of inducing $\mathrm{CD}^{+}{ }^{+} \mathrm{CD} 8{ }^{+} \mathrm{T}$ cells, and it was found 


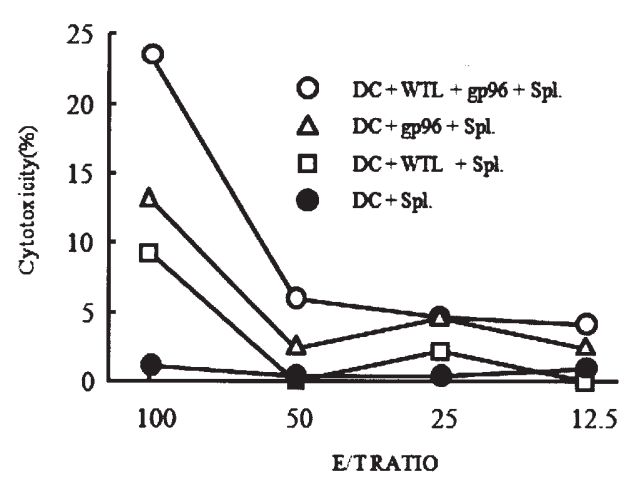

b

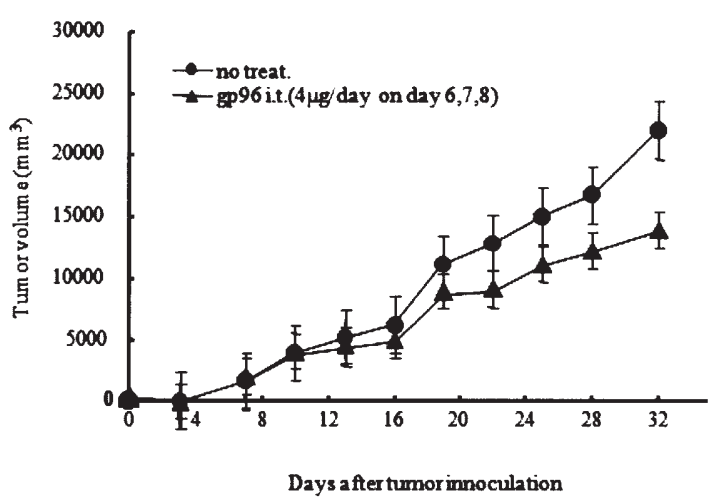

Figure 3. a, Cytotoxicity of mixture of DCs and splenocytes primed with/without WTL and with/without gp96 in vivo. DCs pulsed with both WTL and gp96 showed enhanced antitumor effect (open circles) compared with DCs pulsed only with WTL (open squares). DCs pulsed without WTL did not induce cytotoxicity in this examination. Surprisingly, DCs pulsed only with gp96 also showed enhanced cytotoxicity (open triangles). b, Tumor growth inhibition by gp96 in vivo. SCCVII tumor cells $\left(1 \times 10^{5}\right)$ were inoculated into femur subcutaneous tissue on day 0 . Four micrograms of gp96 was directly administered into tumors 6,7, and 8 days after the inoculation of tumors. Suppression of tumor growth was observed (closed triangles), although complete remission was not observed. Bars \pm SE.

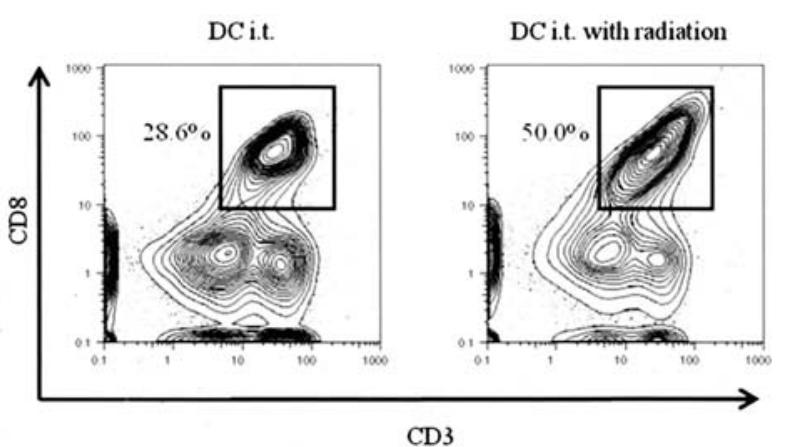

Figure 4. Ionizing radiation can raise $\mathrm{CD} 3^{+} \mathrm{CD} 8^{+} \mathrm{T}$ cells in TDLNs, in vivo. SCCVII cells $\left(1 \times 10^{5}\right)$ were inoculated, and on days 8,9 and $10,1 \times 10^{6}$ DCs were directly injected into the left femur tumor. Shown is the population of $\mathrm{CD}^{+}{ }^{+} \mathrm{CD} 8^{+} \mathrm{T}$ cells in TDLNs. The population of $\mathrm{CD}^{+}{ }^{+} \mathrm{CD} 8^{+} \mathrm{T}$ cells in TDLNs preliminary added with $10 \mathrm{~Gy}$ of irradiation on days 6,7 and 8 is shown on the right. Treatment with DCs only is shown on the left. In mice treated with both DCs i.t. and RT, the population of $\mathrm{CD}^{+}{ }^{+} \mathrm{CD} 8^{+} \mathrm{T}$ cells was 2 times larger than in those treated only with DCs i.t.

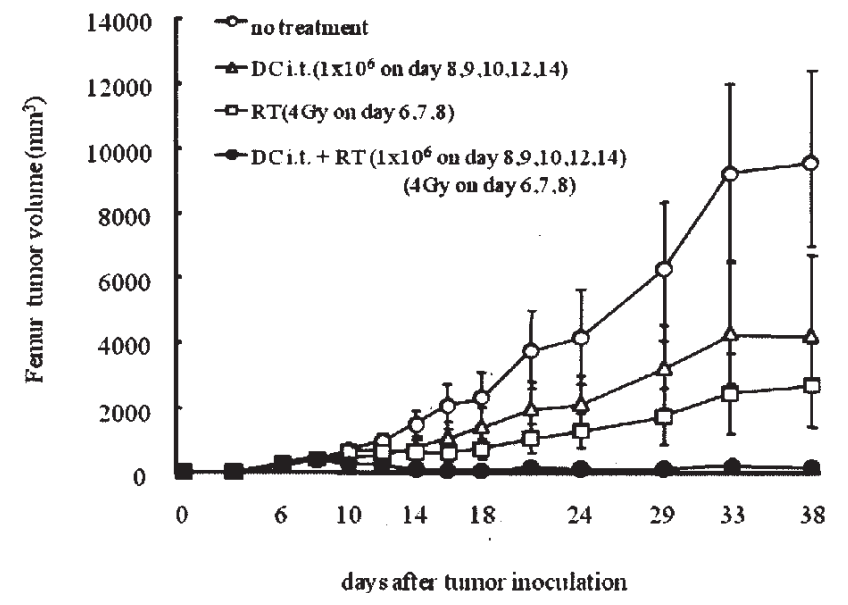

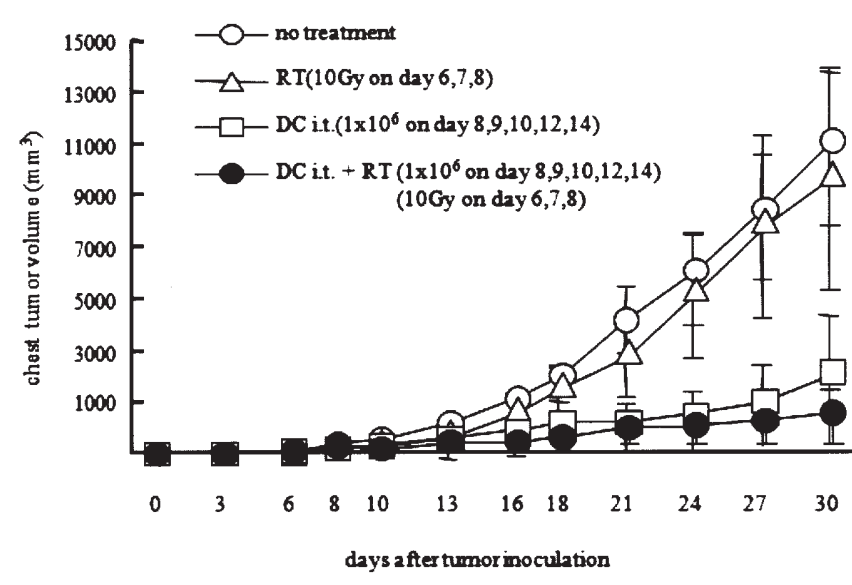

Figure 6. Non-treated tumor growth inhibition mediated by systemic antitumor effect induced by combination of DCs i.t. and RT. SCCVII tumor cells $\left(1 \times 10^{5}\right)$ were inoculated both into left femur subcutaneous tissue and into chest subcutaneous tissue on day 0 . Only the left tumor was treated with DCs i.t. (on days 8, 9, 10,12 and 14) and 10 Gy of RT (on days 6, 7 and 8). Closed circles indicate the chest non-treated tumor volume. The left femur tumor was treated with both DCs i.t. and RT. In these mice, distant nontreated tumor growth was markedly suppressed, compared with mice treated only with DCs i.t. (open squares). Bars \pm SE.

that RT alone could indeed induce that population (data not shown). This may be one of the pieces of evidence that will explain the mechanism of the abscopal effect.

Efficacy of combined therapy of DCs $i . t$ and RT against local treated tumor in vivo. We then examined the antitumor effect by the combination of DCs i.t. and RT against local tumor. The femur tumor grew to a mean size of $1.2 \times 10^{4} \mathrm{~mm}^{3}$ by day 38 . The mean inhibitory rate of growth of femur tumors

Figure 5. The effectiveness of combination therapy of DCs i.t. and RT. SCCVII tumor cells $\left(1 \times 10^{5}\right)$ were inoculated into the left femur subcutaneous tissue. $1 \times 10^{6}$ DCs i.t. (on days 8, 9, 10,12 and 14) following 4 Gy of RT (on days 6, 7 and 8) could almost completely suppress tumor growth (closed circles). The rate of tumor growth suppression was $98.6 \%$. Open triangles indicate tumor volume treated only with DCs i.t., and open squares indicate those treated only with RT. Bars \pm SE. 
treated with DCs i.t. was $50.1 \%$ compared with control mice. The mean inhibitory rate of tumors treated with RT alone was $72.3 \%$ compared with control. The mean inhibitory rate of tumors treated with DCs i.t. and RT was $98.6 \%$ compared with control. Thus, the combination therapy of DCs i.t. and RT showed the strongest antitumor effect in vivo (Fig. 5).

The efficacy of combined therapy of DCs i.t. and RT against non-treated distant tumor in vivo. We investigated whether the combination of direct DCs i.t. and RT could elicit a systemic antitumor effect. As seen in Fig. 6, the mean inhibitory rate of tumors treated only with DCs i.t. was $74.4 \%$, and that with DCs i.t. and RT was $87.3 \%$, the strongest. With RT only, the inhibitory rate was $10.8 \%$ compared with normal control. This phenomenon was thought to be the abscopal effect.

\section{Discussion}

In 1953, the abscopal effect, which was defined as a significant tissue response to radiation that occurs beyond the radiation field, was first reported by Mole (8). He proposed the term 'abscopal', derived from the Latin prefix $a b$ - 'position away from' and -scopos 'mark or target for shooting at'. This mechanism is partly revealed by the fact that ionizing radiation induces the release of cytokines or other inflammatory factors in the circulation $(18,19)$, or that it induces tumor cell death and generates inflammatory signals that mediate direct effects on tumor-associated vessels and also enhance the permeability of solid tumors to both DCs and CTLs $(20,21)$. Recent studies suggested that the mechanism of the abscopal effect is T-cell mediated (7), or that it is mediated by engagement of the Fas/Fas ligand pathway (22), but it still remains poorly understood.

We think one key molecule, by which the abscopal effect induces systemic antitumor immune reaction, is gp96. Gp96 is a major member of the heat shock protein 90 family $(23,24)$ induced by several stresses, resides in the endoplasmic reticulum, and works as a protein chaperone. As seen in Fig. 2, RT has the ability to induce the expression of gp96 in the cytoplasm and also cell ballooning in vitro. DCs reportedly acquire antigen both from apoptotic and necrotic cells (25-27) to induce class I-restricted CTLs. However, we cannot conclude that the ballooning of irradiated SCCVII cells will lead to apoptosis or necrosis, and we cannot answer the question of which is the better source of antigens to induce CTLs. Gp96 plays an important role when DCs take up antigens. First, the tumor antigen and gp96 are combined and form gp96-antigen complex. Following this, the complex is taken up by DCs via CD91 (gp96 receptor) expressed on DCs $(9-12,28,29)$ mediated by Toll-like receptor 2 and 4 (13). By these processes, DCs are matured and then induce CD ${ }^{+}$CTL activation (30) by cross-presentation (31), a mechanism equally reported in human $(32,33)$. Our findings demonstrated that DCs pulsed with gp96 could exert a stronger cytotoxic effect in vitro and gp96 i.t. could induce slight tumor growth inhibition in vivo (Fig. 3).

Overexpressed gp96 by radiation induced CD8 ${ }^{+}$CTLs in TDLNs, as seen in Fig. 4. As others have reported $(29,34,35)$, gp96 potentially boosts the activity of the systemic antitumor effect by these CTLs, and this mechanism could be one explanation for the abscopal effect. In brief, the amount of gp96 is important, although gp96 exists naturally in ordinary normal cells. On the other hand, our data showed only slight tumor suppression by gp96 i.t., confirming the recent reports that non-tumor-derived gp96 cannot induce strong antitumor immunity in vivo $(36,37)$. We used purified gp-96 that was non-tumor derived, so the direct injection of non-tumorderived gp96 was not sufficient for tumor growth inhibition. This suggests that a stronger antitumor effect might be attained if we used the SCCVII tumor-derived gp96. These data imply that the important factor in inducing the activation of DCs is not only the amount of gp96 but also its source.

DC-based immunotherapy results in significant tumor response in various types of tumors. The administered agents are patient-oriented, meaning that toxic adverse effects would presumably be reduced. In this regard, DC-based immunotherapy is quite gentle for patients. However, it is not always completely effective in clinical trials based on immunotherapy alone, as cancer cells often escape from the immune system of the host. Thus, the major problem of poor antigenicity of the tumor can not be ignored. The precise reason why cancer cells escape from the immune system is still unclear, but poor antigenicity is certainly involved. Several attempts have been made to overcome this problem (38-41). As Teitz-Tennenbaum et al reported, ionizing radiation is one of the candidates for potentiating the therapeutic efficacy of DCs i.t. (42). Likewise, this has been supported by Lugade et al (43), who showed that RT induces a greater capability of tumor cells to present tumor antigens on their surface and enhance specific T cells in TDLNs. Such combinational treatments have been reported as useful in some other malignancies, such as fibrosarcoma (44), breast cancer (45) and melanoma (42).

SCC is known to possess sensitivity for RT, so that strong efficacy of the combination of DCs i.t. and RT, which can produce tumor antigens by apoptosis and/or necrosis of tumor cells, and also induces the abscopal effect against SCC, can be expected. A second important strategy is direct DCs i.t. This technique has two major benefits. First, it is profitable for antigen up-taking by DCs. DCs i.t. is lucrative because DCs can be pulsed with a wide range of antigens, such as WTL, proteins, peptides, DNA, and RNA. Second, it is efficient for direct trafficking into tumor, and this means that the trafficking loss of DCs administered is minimized $(40,45,46)$. Moreover, a DC-pulsing procedure is thus unnecessary for DCs i.t. DCs i.t with RT could induce stronger antitumor effect against local tumors compared with tumors treated with simply DCs i.t., as our data show in Fig. 5. This point is the most important for cancer treatment, as the combination of DCs i.t. and RT exerted a precise effect against distant non-treated tumors (Fig. 6), meaning that this combination can evoke a strong systemic antitumor reaction thought to be mediated by the abscopal effect.

Head and neck and esophageal cancers are still among the worst, and deadly, malignant neoplasms, especially in Asia. These cancers have the tendency to metastasize easily to lymph nodes $(29,47)$, the major reason for their miserable prognoses, in spite of the recent improvements in early-stage detection (48) or in advanced-stage treatment. The urgency for the development of an effective treatment is very clear. 
At present, chemotherapy is the only systemic treatment method for SCC, but it tends to lead to a severe immunosuppressed condition of the patient, and its performance is far from satisfactory, as the highly frequent incidents of adverse events cannot be ignored. Our therapeutic model of DCs i.t.-based immunotherapy with RT presents a useful and effective therapeutic modality not only for local tumor but also systemic metastases. RT is routinely and easily performed, and the direct i.t. technique can also be quite readily performed via endoscope or intervention techniques. DCs i.t. with RT treatment is certain to become a treatment modality with much promise for SCC cancer patients in the near future.

\section{Acknowledgments}

This research was supported by a Grant-in-Aid for Young Scientists (B) 17790906, the Ministry of Education, Culture, Sports, Science and Technology, Japan. We also greatly thank Professor Yuta Shibamoto for kindly providing SCCVII tumor cells for our experiments.

\section{References}

1. Friedman EJ: Immune modulation by ionizing radiation and its implications for cancer immunotherapy. Curr Pharm Des 8: 1765-1780, 2002

2. Chakravarty PK, Alfieri A, Thomas EK, et al: Flt3-ligand administration after radiation therapy prolongs survival in a murine model of metastatic lung cancer. Cancer Res 59: 6028-6032, 1999.

3. Belli F, Testori A, Rivoltini L, et al: Vaccination of metastatic melanoma patients with autologous tumor-derived heat shock protein gp96-peptide complexes: clinical and immunologic findings. J Clin Oncol 20: 4169-4180, 2002.

4. Janetzki S, Palla D, Rosenhauer V, Lochs H, Lewis JJ and Srivastava PK: Immunization of cancer patients with autologous cancer-derived heat shock protein gp96 preparations: a pilot study. Int J Cancer 88: 232-238, 2000.

5. Mazzaferro V, Coppa J, Carrabba MG, et al: Vaccination with autologous tumor-derived heat shock protein gp96 after liver resection for metastatic colorectal cancer. Clin Cancer Res 9: 3235-3245, 2003.

6. Larsson M, Fonteneau JF and Bhardwaj N: Dendritic cells resurrect antigens from dead cells. Trends Immunol 22: 141-148, 2001.

7. Demaria $\mathrm{S}, \mathrm{Ng} \mathrm{B}$, Devitt $\mathrm{ML}$, et al: Ionizing radiation inhibition of distant untreated tumors (abscopal effect) is immune mediated. Int J Radiat Oncol Biol Phys 58: 862-870, 2004.

8. Mole RH: Whole body irradiation; radiobiology or medicine? Br J Radiol 26: 234-241, 1953.

9. Zheng H, Dai J, Stoilova D and Li Z: Cell surface targeting of heat shock protein gp96 induces dendritic cell maturation and antitumor immunity. J Immunol 167: 6731-6735, 2001.

10. Binder RJ and Srivastava PK: Essential role of CD91 in representation of gp96-chaperoned peptides. Proc Natl Acad Sci USA 101: 6128-6133, 2004.

11. Binder RJ, Han DK and Srivastava PK: CD91: a receptor for heat shock protein gp96. Nat Immunol 1: 151-155, 2000.

12. Facciponte JG, Wang XY, MacDonald IJ, et al: Heat shock proteins HSP70 and GP96: structural insights. Cancer Immunol Immunother 55: 339-346, 2006.

13. Vabulas RM, Braedel S, Hilf N, et al: The endoplasmic reticulum-resident heat shock protein Gp96 activates dendritic cells via the Toll-like receptor $2 / 4$ pathway. J Biol Chem 277: 20847-20853, 2002.

14. Khurana D, Martin EA, Kasperbauer JL, et al: Characterization of a spontaneously arising murine squamous cell carcinoma (SCC VII) as a prerequisite for head and neck cancer immunotherapy. Head Neck 23: 899-906, 2001.

15. Lutz MB, Kukutsch N, Ogilvie AL, et al: An advanced culture method for generating large quantities of highly pure dendritic cells from mouse bone marrow. J Immunol Methods 223: 77-92, 1999.
16. Kawano T, Cui J, Koezuka Y, et al: Natural killer-like nonspecific tumor cell lysis mediated by specific ligand-activated Valpha14 NKT cells. Proc Natl Acad Sci USA 95: 5690-5693, 1998.

17. Baker-LePain JC, Sarzotti M, Fields TA, Li CY and Nicchitta CV: GRP94 (gp96) and GRP94 N-terminal geldanamycin binding domain elicit tissue nonrestricted tumor suppression. J Exp Med 196: 1447-1459, 2002.

18. Ohba K, Omagari K, Nakamura T, et al: Abscopal regression of hepatocellular carcinoma after radiotherapy for bone metastasis. Gut 43: 575-577, 1998.

19. Camphausen K, Moses MA, Menard C, et al: Radiation abscopal antitumor effect is mediated through p53. Cancer Res 63: 1990-1993, 2003.

20. Nikitina EY and Gabrilovich DI: Combination of gammairradiation and dendritic cell administration induces a potent antitumor response in tumor-bearing mice: approach to treatment of advanced stage cancer. Int J Cancer 94: 825-833, 2001.

21. Ganss R, Ryschich E, Klar E, Arnold B and Hammerling GJ: Combination of $\mathrm{T}$-cell therapy and trigger of inflammation induces remodeling of the vasculature and tumor eradication. Cancer Res 62: 1462-1470, 2002.

22. Chakraborty M, Abrams SI, Coleman CN, Camphausen K, Schlom J and Hodge JW: External beam radiation of tumors alters phenotype of tumor cells to render them susceptible to vaccine-mediated T-cell killing. Cancer Res 64: 4328-4337, 2004.

23. Fairburn B, Muthana M, Hopkinson K, et al: Analysis of purified gp96 preparations from rat and mouse livers using 2-D gel electrophoresis and tandem mass spectrometry. Biochimie: 2006 .

24. Sastry S and Linderoth N: Molecular mechanisms of peptide loading by the tumor rejection antigen/heat shock chaperone gp96 (GRP94). J Biol Chem 274: 12023-12035, 1999.

25. Albert ML, Sauter B and Bhardwaj N: Dendritic cells acquire antigen from apoptotic cells and induce class I-restricted CTLs. Nature 392: 86-89, 1998.

26. Sauter B, Albert ML, Francisco L, Larsson M, Somersan S and Bhardwaj N: Consequences of cell death: exposure to necrotic tumor cells, but not primary tissue cells or apoptotic cells, induces the maturation of immunostimulatory dendritic cells. J Exp Med 191: 423-434, 2000.

27. Kotera Y, Shimizu K and Mule JJ: Comparative analysis of necrotic and apoptotic tumor cells as a source of antigen(s) in dendritic cell-based immunization. Cancer Res 61: 8105-8109, 2001 .

28. Demine R and Walden P: Testing the role of gp96 as peptide chaperone in antigen processing. J Biol Chem 280: 17573-17578, 2005.

29. Ramirez SR, Singh-Jasuja H, Warger T, et al: Glycoprotein 96activated dendritic cells induce a CD8-biased $\mathrm{T}$ cell response. Cell Stress Chaperones 10: 221-229, 2005.

30. Segal BH, Wang XY, Dennis CG, et al: Heat shock proteins as vaccine adjuvants in infections and cancer. Drug Discov Today 11: 534-540, 2006.

31. Doody AD, Kovalchin JT, Mihalyo MA, Hagymasi AT, Drake CG and Adler AJ: Glycoprotein 96 can chaperone both MHC class I- and class II-restricted epitopes for in vivo presentation, but selectively primes $\mathrm{CD}^{+} \mathrm{T}$ cell effector function. J Immunol 172: 6087-6092, 2004.

32. Laad AD, Thomas ML, Fakih AR and Chiplunkar SV: Human gamma delta $\mathrm{T}$ cells recognize heat shock protein-60 on oral tumor cells. Int J Cancer 80: 709-714, 1999.

33. Rivoltini L, Castelli C, Carrabba M, et al: Human tumor-derived heat shock protein 96 mediates in vitro activation and in vivo expansion of melanoma- and colon carcinoma-specific T cells. $\mathrm{J}$ Immunol 171: 3467-3474, 2003.

34. Wang XH, Qin Y, Hu MH and Xie Y: Dendritic cells pulsed with gp96-peptide complexes derived from human hepatocellular carcinoma (HCC) induce specific cytotoxic T lymphocytes. Cancer Immunol Immunother 54: 971-980, 2005.

35. Liu S, Wang H, Yang Z, et al: Enhancement of cancer radiation therapy by use of adenovirus-mediated secretable glucoseregulated protein 94/gp96 expression. Cancer Res 65: 9126-9131, 2005 .

36. Tamura Y, Peng P, Liu K, Daou M and Srivastava PK: Immunotherapy of tumors with autologous tumor-derived heat shock protein preparations. Science 278: 117-120, 1997. 
37. Ueda G, Tamura Y, Hirai I, et al: Tumor-derived heat shock protein 70-pulsed dendritic cells elicit tumor-specific cytotoxic T lymphocytes (CTLs) and tumor immunity. Cancer Sci 95: 248-253, 2004.

38. Ahmed SU, Okamoto M, Oshikawa T, et al: Anti-tumor effect of an intratumoral administration of dendritic cells in combination with TS-1, an oral fluoropyrimidine anti-cancer drug, and OK-432, a streptococcal immunopotentiator: involvement of toll-like receptor 4. J Immunother 27: 432-441, 2004.

39. Tong Y, Song W and Crystal RG: Combined intratumoral injection of bone marrow-derived dendritic cells and systemic chemotherapy to treat pre-existing murine tumors. Cancer Res 61: 7530-7535, 2001.

40. Schmidt T, Ziske C, Marten A, et al: Intratumoral immunization with tumor RNA-pulsed dendritic cells confers antitumor immunity in a C57BL/6 pancreatic murine tumor model. Cancer Res 63: 8962-8967, 2003.

41. Tanaka F, Yamaguchi H, Ohta M, et al: Intratumoral injection of dendritic cells after treatment of anticancer drugs induces tumor-specific antitumor effect in vivo. Int J Cancer 101: 265-269, 2002.

42. Teitz-Tennenbaum S, Li Q, Rynkiewicz S, et al: Radiotherapy potentiates the therapeutic efficacy of intratumoral dendritic cell administration. Cancer Res 63: 8466-8475, 2003.
43. Lugade AA, Moran JP, Gerber SA, Rose RC, Frelinger JG and Lord EM: Local radiation therapy of B16 melanoma tumors increases the generation of tumor antigen-specific effector cells that traffic to the tumor. J Immunol 174: 7516-7523, 2005.

44. Kim KW, Kim SH, Shin JG, et al: Direct injection of immature dendritic cells into irradiated tumor induces efficient antitumor immunity. Int J Cancer 109: 685-690, 2004.

45. Candido KA, Shimizu K, McLaughlin JC, et al: Local administration of dendritic cells inhibits established breast tumor growth: implications for apoptosis-inducing agents. Cancer Res 61: 228-236, 2001.

46. Triozzi PL, Khurram R, Aldrich WA, Walker MJ, Kim JA and Jaynes S: Intratumoral injection of dendritic cells derived in vitro in patients with metastatic cancer. Cancer 89: 2646-2654, 2000.

47. Bollschweiler E, Baldus SE, Schroder W, et al: High rate of lymph-node metastasis in submucosal esophageal squamouscell carcinomas and adenocarcinomas. Endoscopy 38: 149-156, 2006.

48. Mayinger B, Horner P, Jordan M, et al: Light-induced autofluorescence spectroscopy for the endoscopic detection of esophageal cancer. Gastrointest Endosc 54: 195-201, 2001. 